\title{
COMPARING ATMOSPHERIC CORRECTION PERFORMANCE FOR SENTINEL-2 AND LANDSAT-8 DATA
}

\author{
Bringfried Pflug ${ }^{(1)}$, Rudolf Richter ${ }^{(1)}$, \\ Raquel de los Reyes ${ }^{(1)}$, Peter Reinartz ${ }^{(1)}$ \\ (1) German Aerospace Centre, Remote Sensing Technology Institute \\ email: bringfried.pflug@dlr.de, rudolf.richter@dlr.de, raquel.delosreyes@dlr.de, peter.reinartz@dlr.de
}

\begin{abstract}
Most remote sensing applications require atmospheric correction of satellite images and an increasing part exploits multi-temporal data. Sentinel-2 satellites and Landsat-8 provide almost equivalent satellite images and a joint use of both data sources gives the advantage of a denser time series if the quality of atmospheric correction is consistent. The present study investigates the performance of atmospheric correction processor ATCOR and shows, that it gives consistent results for Sentinel-2 and Landsat-8 data enabling a combined use of both satellites. Both satellite sensors provide the same correct shape of surface reflection spectra.
\end{abstract}

Index Terms - Atmospheric correction, Sentinel-2, Landsat-8, ATCOR, PACO, validation

\section{INTRODUCTION}

Observation of the Earth surface by satellite images in the optical domain is influenced by scattering and absorption due to gases and particles in the atmosphere. Removing these effects is called atmospheric correction, resulting in Level-2A-products. Atmospheric correction is necessary for many applications of remote sensing, i.e. observing landcover change, deriving biophysical variables related to agriculture and forestry, monitoring coastal and inland waters and it is useful for risk and disaster mapping [1].

With both Sentinel-2 satellites [1] and Landsat-8 [2] in orbit there is a dense time series of satellite images available which can be combined to provide information about the Earth surface. Sentinel-2 and Landsat- 8 images have approximately equivalent spectral bands and only little different spatial resolution of $10 \mathrm{~m} / 20 \mathrm{~m}$ and $30 \mathrm{~m}$ [3]. Radiometric accuracy of Sentinel-2 MSI is 3\% and radiometric performance of both imaging instruments agree within 3\% [4].

The value of the combined use of both satellites strongly depends on the quality of L2A-products. The present paper investigates the atmospheric correction performance of atmospheric correction tool ATCOR [5] applied to
Sentinel-2 and Landsat-8 images. ATCOR is a widely used atmospheric correction tool which can process data of many optical satellite sensors including Sentinel-2 and Landsat-8.

Quality assessment of ATCOR follows the same approach as is used for quality assessment of atmospheric correction processor Sen2Cor [6, 7, 8]. Aerosol optical thickness at $550 \mathrm{~nm}\left(\mathrm{AOT}_{550}\right)$ and water vapour (WV) retrieval can be validated by direct comparison of the output of the atmospheric correction processor with reference values provided by AERONET sun photometers [9]. Performance assessment of surface reflectance (SR) estimation is more difficult. The present study is based on measurements on the ground as a reference, which were collected during an ad-hoc campaign. The advantage of using those data is that real measurements are used as reference. The disadvantages are that campaigns provide reference data only for a very small amount of pixels and that the upscaling of surface reflection measurements to satellite pixels introduces additional errors. An alternative is using so called AERONET corrected surface reflectance as reference [10]. This reference is computed from Satellite L1C TOA products using a radiation transport model with AERONET aerosol data as input. This method provides a huge number of reference pixels for analysis, but the reference is influenced by the radiation transport model included and is not a measurement. The comparison of Sentinel-2 and Landsat- 8 data on basis of AERONET corrected surface reflection is not part of the present study, but will be done in future to complement this analysis.

\section{TEST DATA SET}

Present analysis for AOT retrieval is based on the data set defined and used for the $1^{\text {st }}$ Atmospheric Correction Intercomparison Exercise (ACIX-1) [11]. This data set includes 15 AERONET sites around the world covering different land surface types, various climate zones and cloud coverage up to $50 \%$. The four water sites are excluded from the present analysis. Whereas the data set used for Landsat- 8 covers a full year, the data set for Sentinel-2A was limited to a seven-month period from December 2015 to June 2016 not covering all seasons. 
Analysis for SR retrieval is based on data of an ad-hoc campaign which took place over North-East Germany on $4^{\text {th }}$ May 2018. Collocated images of Sentinel-2B and Landsat-8 are acquired on this day together with reference measurements on the ground.

\section{AEROSOL OPTICAL THICKNESS RETRIEVAL PERFORMANCE}

AOT $_{550}$ retrieval with ATCOR is based on a Dense Dark Vegetation (DDV) pixel approach [5]. If the image to correct contains less than $2 \%$ DDV-pixels, $\mathrm{AOT}_{550}$ cannot be estimated from the satellite data and a fall-back solution has to be used for correction of the image. The present fallback solution corrects the image with a pre-defined, fixed value for $\mathrm{AOT}_{550}$. Therefore the complete data set was split into a DDV-subset and a non-DDV-subset for analysis.

\subsection{AOT retrieval performance for Sentinel-2 data}

The accuracy specification defined for Sen2Cor [7] is used in this study as a performance indicator for AOT-retrieval. Figure 1 shows a correlation plot of $\mathrm{AOT}_{550}$ retrieval results at $20 \mathrm{~m}$ spatial resolution with reference from an AERONET sun photometer. The results for the DDV-subset are plotted with green triangles and for non-DDV subset with orange triangles. There are many $\mathrm{AOT}_{550}$ retrievals for the nonDDV subset giving $\mathrm{AOT}_{550}$ at 0.36 because of processing with fixed visibility. Lower $\mathrm{AOT}_{550}$ retrievals are due to higher elevation of the test site above sea level or due to a check in the AOT retrieval algorithm for negative reflectance pixels. If there are more than $1 \%$ pixels with negative reflectance in the image, then the AOT is decreased step by step until this threshold is reached.

The DDV-algorithm gives $56 \%$ of results within the accuracy specification defined for Sen2Cor and suggests a tendency for larger underestimation than overestimation of $\mathrm{AOT}_{550}$. The algorithm shows good accuracy with a mean bias of -0.01 and an acceptable precision value (repeatability) of 0.06 . Both result in uncertainty (RMSD) of 0.06 . The Pearson's correlation coefficient for the subset is 0.67 .

\subsection{AOT retrieval performance for Landsat-8 data}

$\mathrm{AOT}_{550}$ retrieval for the Landsat- 8 data set gives similar results as the Sentinel-2 data set. It is intended to update this section with a figure and statistical values for Landsat-8 equivalent to the previous section.

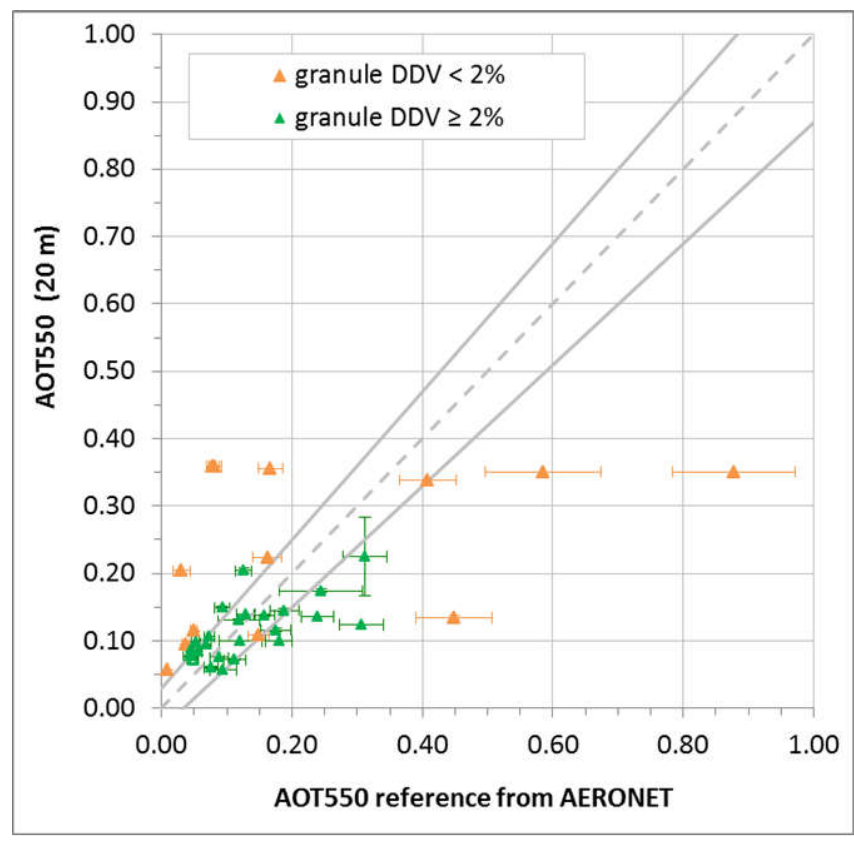

Figure 1: Correlation plot of $\mathrm{AOT}_{550}$ retrieval for Sentintel-2 data at $20 \mathrm{~m}$ resolution over $\mathrm{AOT}_{550}$ reference from AERONET on basis of a data set at 15 AERONET sites. Green triangles are $\mathrm{AOT}_{550}$ values retrieved with the DDV-algorithm and orange triangles are $\mathrm{AOT}_{550}$ resulting from the present fall-back solution (process with configured start VIS of $20 \mathrm{~km}$ ). The dashed grey line indicates $\mathrm{x}=\mathrm{y}$ and the solid grey lines show the limits of the accuracy specification $\mid \Delta$ AOT550 $\mid \leq 0.1 *$ AOT550ref +0.03 .

\section{SURFACE REFLECTANCE RETRIEVAL PERFORMANCE}

Quantitative assessment of SR retrieval is investigated by comparing example spectra of Sentinel-2 and Landsat-8 sensors extracted from collocated images for different surface cover types. Both images are acquired on the same day with only $10 \mathrm{~min}$ difference in overpass time. AOT $_{550}$ retrieved from both images is very near to each other. $\mathrm{AOT}_{550}$ estimated from Sentinel-2 data is 0.09, estimated from Landsat -8 data is 0.11 and the reference from a sun photometer is 0.07 .

Example spectra were extracted for both satellites for the same regions of interest with size of about $120 \times 120 \mathrm{~m}^{2}$. Spectra from Landsat- 8 are corrected for spectral differences between Landsat- 8 and Sentinel-2B by applying an adjustment factor determined from surface reflection measurements on the ground. BRDF-effects are neglected in this study. Figure 2 shows that SR spectra originating from Sentinel-2B and Landsat-8 agree very well. Most of the shape of spectra is almost identical with Pearson's correlation coefficient above 0.98 except for water. The correlation coefficient is 0.54 over water due to differences 
found between Sentinel-2B and Landsat- 8 SR spectra in the NIR spectral range and the generally low reflectance values. On the other side, RMSE between both sensors over water is lower than over land. RMSE over water is 0.005 compared to RMSE between 0.007 and 0.09 over vegetation and 0.02 over a village.

SR measurements are available over grass surface for the investigated overpasses of Sentinel-2 and Landsat- Both sensors have again a high correlation above 0.98 relative to the SR measurements over grass and an RMSE of about 0.04. This shows that they provide the same correct shape of spectra even if the magnitude of the resulting spectra has an offset to the measured reference spectrum. Note, that the upscaling of the reference spectrum to satellite pixels is still ongoing work.

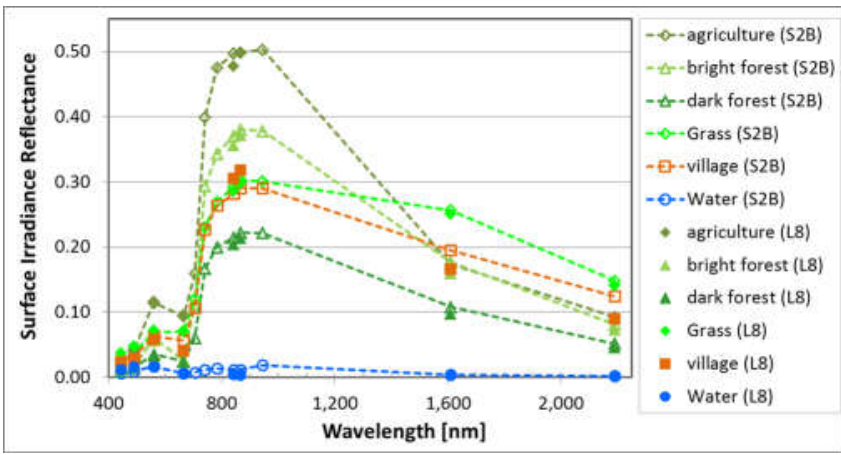

Figure 2: Example spectra of different surface types extracted from images of Sentinel-2B and Landsat-8 acquired over North-East Germany on the same day.

\section{DISCUSSION}

$\mathrm{AOT}_{550}$ retrieval performance of ATCOR for the campaign data is well within accuracy specification for Sentinel-2 and at the boarder of accuracy specification for Landsat- 8 . This good $\mathrm{AOT}_{550}$ retrieval performance for both sensors leads to very close agreement of atmospherically corrected SR spectra shown in Figure 2. However, even then it is worth to discuss the differences between SR retrieved from Sentinel-2 and Landsat-8 in more detail (Fig. 3). Lowest differences occur over water surface as expectable from RMSE mentioned above. Generally, differences are smaller in the VIS spectral range than in the NIR and SWIR. Largest differences between S2B and Landsat-8 occur for urban areas.

The ratio between SR obtained from both sensors is lower in the NIR than in the VIS due to the larger SR in that range. It is within $5 \%$ for the grass spectrum except bands 1 and 2 and mostly within $10 \%$ for other surface types and bands.

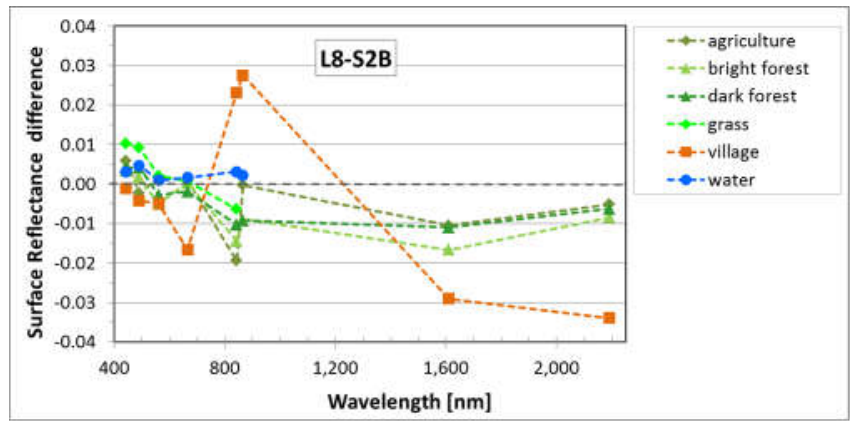

Figure 3: Differences between example spectra of several surface types extracted from images of Sentinel-2B and Landsat-8 acquired over North-East Germany on the same day.

\section{CONCLUSION}

Atmospheric correction with ATCOR gives consistent results for Sentinel-2 and Landsat-8 data enabling a combined use of both satellites. They provide the same correct shape of spectra even if the magnitude of the resulting spectra has an offset to a measured reference spectrum.

The present paper investigates the atmospheric correction performance of the atmospheric correction tool ATCOR applied to Sentinel-2 and Landsat- 8 images. Parallel to maintenance and evolution of ATCOR itself the main ATCOR modules are being migrated to Python-based Atmospheric COrrection chain PACO. PACO is an improved version of the software which took part in ACIX-1 [11] with the name S2-AC2020. It is designed for Big-Data solutions and being Python-based it alleviates the software maintenance and interoperability. PACO will provide the same performance as ATCOR.

\section{ACKNOWLEDGMENTS}

We would like to thank the AERONET sun-photometer network and their PIs for their important observations.

\section{REFERENCES}

[1] Drusch, M., Del Bello, U., Carlier, S., et al. (2012). "Sentinel2: ESA's Optical High-Resolution Mission for GMES Operational Services", Remote Sensing of Environment, 120, 25-36

[2] Roy, D.P., et al.(2014). "Landsat-8: Science and product vision for terrestrial global change research", Remote Sensing of Environment, 145, 154-172

[3] Zhang, H.K.K., et al. (2018). "Characterization of Sentinel-2A and Landsat- 8 top of atmosphere, surface, and nadir BRDF adjusted reflectance and NDVI differences", Remote Sensing of Environment, 215, 482-494 
[4] Sentinel-2 MPC Team (2019). "Sentinel-2 L1C Data Quality Report (S2-PDGS-MPC-L1CDQR)”, Issue 34, 08 January 2019]; Available from: https://earth.esa.int/web/sentinel/userguides/sentinel-2-msi/document-library/. Accessed on 08/01/2019

[5] Richter, R. (1996). "A spatially adaptive fast atmospheric correction algorithm", Int. J. Remote Sensing, Vol. 17, 1201-1214

[6] Gascon F., Bouzinac, C., Thépaut, O., et al. (2017). "Copernicus Sentinel-2A Calibration and Products Validation Status”, Remote Sens., 9(6), 584; doi:10.3390/rs9060584

[7] Pflug, B., Louis, J., Main-Knorn, M., Debaecker, V., MuellerWilms, U., Gascon, F. and Vermote, E. (2018). "Accuracy and Uncertainty of Sen2Cor Bottom-of-Atmosphere Product", 38th Annual EARSeL Symposium, 9.-12. July 2018, Chania, Crete, Greece.

[8] Louis, J., Pflug, B., Main-Knorn, M., Debaecker, V., MuellerWilm, U., Iannone, R.Q., Cadau, E.G., Boccia, V. and Gascon, F. (2019) Sentinel-2 global surface reflectance level-2A product generated with Sen2Cor. In: 2019 IEEE International Geoscience and Remote Sensing Symposium (IGARSS), IGARSS 2019, 28 July - 2 August 2019, Yokohama, Japan.

[9] Holben, B.N.; Eck, T.F.; Slutker, I.; Tanré, D.; Buis, J.P.; Setzer, A.; Vermote, E.; Reagan, J.A.; Kaufman, Y.J.; Nakajima, T.; et al. (1998), "AERONET - A federated instrument network and data archive for aerosol characterization", Remote Sens. Env. 66, 1-16, doi:10.1016/S0034-4257(98)00031-5.

[10] Claverie, M., et al. (2015). "Evaluation of the Landsat-5 TM and Landsat-7 ETM + surface reflectance products", Remote Sensing of Environment, 169, 390-403.

[11] G. Doxani et al. (2018), "Atmospheric Correction InterComparison Exercise", Remote Sensing, 10 (352), pp 1-18. DOI: doi:10.3390/rs10020352 ISSN 2072-4292 